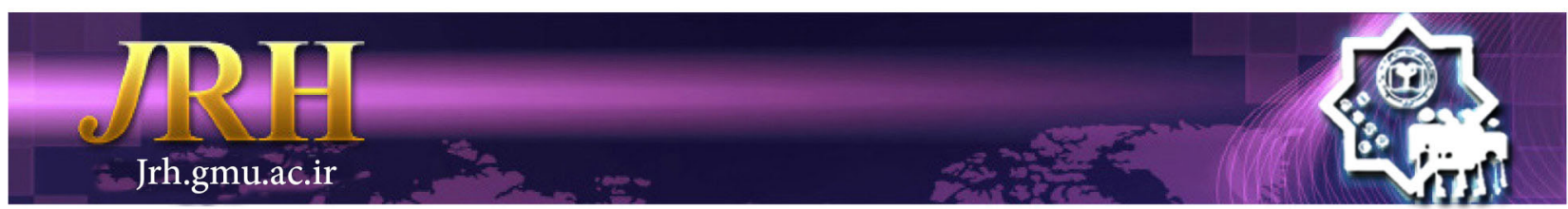

\title{
Trust in physician, satisfaction with physician and their relationship among diabetic patients in Kerman, Iran
}

Leila Rahimpour ${ }^{1}$, Saideh Garousi², Soodeh Maghsoodi ${ }^{2}$

Journal of Research \& Health

Social Development \& Health Promotion Research Center

Vol. 8, No. 4, Jul \& Aug 2018

Pages: $373-381$

DOI: 10.29252/jrh.8.4.373

Original Article

1. Research Center for Tropical and Infectious Diseases, Kerman University of Medical Sciences, Kerman, Iran

2. Department of Social Sciences, Literature and Humanities Faculty, University of Shahid Bahonar, Kerman, Iran

Correspondence to: Saideh Garousi, Department of Social Sciences, Literature and Humanities Faculty, University of Shahid Bahonar, Kerman, Iran

Email: sgarousi@uk.ac.ir

Received: 3 Jul 2014

Accepted: 2 Feb 2015

How to cite this article: Rahimpour L, Garousi S, Maghsoodi S. Trust in physician, satisfaction with physician and their relationship among diabetic patients in Kerman, Iran. $J$ Research Health2018; 8(4): 373- 381.

\begin{abstract}
Physician-patient relationship is one of the effective factors in satisfaction with medical services. One of the key elements of this relationship is the patient's trust in the physician, which can increase patient satisfaction with the physician. The purpose of this study was to investigate the effect of patient trust on satisfaction with physicians. This cross-sectional study recruited 400 diabetic patients. Data were collected by using questionnaires and interviews. The questionnaire was validated through face validity and internal consistency of its items. The results showed that there is a significant relationship between trust in the physician and satisfaction with the physician. Regression analysis showed that the variables of global trust, dutifulness, honesty, confidentiality, and competence had the greatest impact on the variable of patient satisfaction with the physician, respectively. According to the results of the study, it is recommended that more emphasis be placed on how to create and maintain mutual trust in medical education, such that more patient satisfaction is achieved in the competitive and customer-oriented care system, and also prepare the patient for better response to the treatment.
\end{abstract}

Keywords: Physician, Relationship, Satisfaction, Trust

\section{Introduction}

Patient-physician relationship is an important issue in healthcare and involves profound cultural, social and psychological aspects. This relationship is considered a major component of medical contacts and the key to patient satisfaction and adaptation to the treatment [1]. Patient-physician relationship results in patient satisfaction, psychological adjustment, and progress in treatment. Therefore it can help improve health [2].

In the past, the physician was the center of the relationship as an experienced and professional specialist, but in recent years the focus has shifted onto the patient's desires, expectations, and satisfaction by development of patient-oriented medicine [3]. Today's researches showed that the patient is more willing to cooperate with the physician [4]. The elements that make up the physicianpatient relationship include understanding patient's feeling, guidance, control, trust, and confidence [5]. Patient's trust in the physician 
is considered as one of the most important aspects of patient-physician relationship [6]. Trust can be defined as people's understanding of each other as good, responsible, caring and moral individuals [7]. Trust also includes aspects such as confidentiality and accountability [8]. Researches showed that it is associated with satisfaction with the physician, progress in the treatment, and treatment continuation [9]. Trust is defined in two ways; as a result of a patient-physician relationship, as well as determining the patient satisfaction with the physician and the process [10]. In general, trust can be used as a general basis for recognizing a satisfactory therapeutic relationship. The empathetic interaction of the physician with the patient can lead to the emergence of trust [11]. A trustful patient-physician relationship can potentially increase patient compliance with the treatment process and speed up behavior change [12]. As the progress in relationship, the trust in physician can be strengthened [13]. The emergence of trust is possible through the expansion of interaction and the continuity of treatment. Furthermore, the presence of a longterm physician-patient relationship may only be a sign of a high level of trust.

Hall defined five dimensions for the patient's trust in a physician: 1) Fidelity, which is caring for the patient's interests and avoiding conflicts of interest; 2) Competence, which is having good interpersonal skills and avoiding mistakes; 3) Honesty, which is telling the truth and avoiding intentional falsehoods; 4) Confidentiality, which is proper use of sensitive information; and 5) Global trust, which is the soul of trust [14].

Institutional trust and interpersonal trust are different in medicine. Institutional trust means to trust in a healthcare system in general, while interpersonal trust refers only to the trust arising from the relationship between the patient and caregivers and therapists. Interpersonal trust refers to the optimistic acceptance of vulnerable situations where the patient believes the physician advocates his interests [15]. The terms "trust" and "satisfaction" appear to overlap. However, one must note the nuanced difference between the two. In fact, trust is mostly based on expectations, while satisfaction is based on the evaluation of previous activities [14]. Patient satisfaction is the cognitive and emotional response through which the patient expresses satisfaction of own needs and is now used as a measure of the quality of care and treatment [16]. In fact, patient satisfaction is the response of the individual to the provided service, which reflects his perception of receiving the service [17]. Patient satisfaction leads to the continuity of treatment, the practice of treatment with consent and commitment to the use of prescribed drugs [18].

Researches showed that type of patientphysician relationship is one of the most effective factors that provide patient satisfaction. Of course, confidentiality, careful listening, giving time to the patient, and academic and professional competence are very important [19]. This concept is widely used in patient-physician relationships. In fact, patient satisfaction is considered as the outcome of a patient-physician relationship and patient's voice in this field. Interpersonal aspects of care, including physician's attitudes and communication are considered the main components of patient satisfaction.

Since patient's satisfaction with the treatment process provides the motivation for continuing treatment and timely and correct use of medical prescriptions, which will ultimately lead to the acceleration of recovery and health on the one hand, and the achievement of a positive image of the existing therapeutic process on the other hand [20], it can be concluded that patient satisfaction survey is of particular importance. Diabetes is a chronic disease of a particular concern to the health system for several reasons, including the spread of disease, complications, and the high costs of care and treatment. According to the 2006 data, the prevalence of this disease in Iran was 2-3 percent in total population and 7-8 percent among individuals over the age of 30 . That is, nearly four million people suffer from diabetes [16]. Regarding the relatively high prevalence and chronicity of the disease, it can be predicted that visits to the physician are frequent. The continuation of 
treatment and the use of prescriptions requires patient engagement.

Khadem-Nejad's study showed that patientphysician relationship affects patient satisfaction [19]. The researchers concluded that the degree of satisfaction with the physician was closely related to the interpersonal interactions between the physician and the patient $[16,20]$.

Another study showed that physicians' knowledge of patients' expectations and factors that affect their satisfaction improves patient-physician relationship and quality of healthcare which is the ultimate goal of the health system [21].

Some researches show that the physician can be positively effective in the treatment process such that the diabetes patients who have a high trust in their physician are more self-caregiving and make good advances in controlling the disease [22,23].

Other researchers concluded that gender, education, marital status, and occupation were among the factors influencing the patient satisfaction with the physician. Furthermore, satisfaction with the physician has a high correlation with the loyalty [24-26].

An overview of the studies conducted in Iran and the world shows that although trust in the physician plays an important role in the treatment outcome, little research has been conducted in this regard. Since patients with the chronic disease of diabetes make numerous visits to medical centers, patient-physician relationship and its important aspects such as trust and satisfaction, which contribute to the continuity of the treatment process and the effectiveness of the therapeutic measures, have great importance. Furthermore, it should be noted that in Kerman, and especially among diabetic patients, no research has been conducted on the patient-physician relationship and patient satisfaction. The present study evaluates the extent of trust in the physician and its dimensions, the degree of physician satisfaction and its dimensions, and the relationship between the two variables of trust in the physician and satisfaction with the physician among diabetic patients in Kerman.

\section{Method}

This cross-sectional study recruited diabetic patients treated by specialist physicians in Kerman. Samples were randomly selected among the patients with diabetes (9300 cases). Based on the Cochran formula, the sample size was determined as 384 individuals, and 400 participants were selected to ensure prevention of sample loss. Informed consent was obtained from all participants in the study and then they were interviewed. Data were collected through a questionnaire with interviews. The questionnaire consisted of three main sections. The first part, which was researcher-made, contained 32 items in the form of a five-point Likert scale to measure patient's trust in the physician. The second part contained 36 items in the form of a Likert scale to measure patient satisfaction with the physician. It should be noted that the questionnaire was made by the researchers based on the patient satisfaction domains determined by Marshall and Hays in 1994 [16]. The third part contained items about age, sex, marital status, educational level, income, history of illness, and duration of visiting the physician, type of treatment, physician's gender and physician's age in a multiple choice form at the nominal, ordinal, and interval levels of measurement.

The variable of trust in physician has the components of fidelity, competence, honesty, confidentiality, and global trust. Fidelity means caring for the patient's interests and avoiding conflicts of interest [27]. It has indicators of patient treatment based on expertise, performing the tasks responsible, and availability of the physician. Competence means having good practice and interpersonal skills and avoiding mistakes. It includes scientific, communication and professional dimensions. The skills that a physician must gain are as follows: Good history writing skills, good observation and examination skills, communication skills, certified training skills, the ability to achieve correct differential diagnoses, the ability to use theory in practice and clinic. The honesty variable has indicators of telling the truth to the patients about their 
disease, prescribing proper medication and not referring to a specific pharmacy for personal interests, and lack of interest in one's own interests. Confidentiality needs physicians to consider their patients' information confidential. Confidentiality is the basis of confidence in human communication and is based on patient's expectations from the trust in the physician. Physician's confidentiality creates the patient's necessary confidence to express all the points and secrets of the disease, which is a useful step in diagnosis and treatment [28].

The confidentiality variable has indicators such as advocating the patient's and their family's interests, the limits of telling the truth to the patient, the patient's consent to reveal the facts about the disease, and how to record and store information about the patient's medical record. Global trust is having full confidence in the physician in all of aspects. This variable has the following indicators; full confidence in the physician and their performance and choosing that physician in comparison with the same choices. In this study, the variable of patient satisfaction with the physician was evaluated in three dimensions; cognitive, emotional and behavioral. Cognitive satisfaction refers to the explanations and information provided by the physician to the patient and the patient's understanding of the disease, the prognosis of the disease and the effects of the treatment [29]. Emotional satisfaction refers to the patient's awareness of the therapeutic relationship that includes the feeling of trust and confidence in the physician, the awareness of the physician's positive attention to the patient and the patient satisfaction because of caring for their words. Behavioral satisfaction refers to the patient's assessment of the physician's professional behavior, physical examination of the patient, diagnostic methods, treatment, and medical advice [29].

Face validity was used to evaluate the validity of the tool that is a questionnaire was first provided to several physicians, psychologists, and sociologists. After applying the experts' opinion, internal consistency was used to measure the reliability of the questionnaire. Cronbach's alpha coefficients for the questionnaire were as follows; trust in the physician: 0.77 , fidelity: 0.66 , competence: 0.77 , honesty: 0.75 , confidentiality: 0.82 , global trust: 0.84 , satisfaction with the physician: 0.87 , cognitive satisfaction: 0.89 , emotional satisfaction: 0.85 and behavioral satisfaction: 0.86 .

Descriptive statistics were used to describe the status quo, and correlation and multivariate regression tests were used to analyze the relationships between variables by SPSS-20.

\section{Results}

In this study, $60.8 \%$ of the participants were female and 39.2 were male. The mean age of the participants was 40.8 years. Among them, $75.2 \%$ were married and the majority of them expressed their educational level as high school diploma (36.7\%). Table 1 presents different features of the disease and treatment in participants.

Table 1 Features related to the history of the disease and the treatment of the participants

\begin{tabular}{llcc}
\hline Variable & & Frequency & Percent \\
\hline & 1-5 years & 295 & 73.8 \\
& 6-10 years & 62 & 15.5 \\
History of & 11-15 years & 23 & 5.7 \\
the disease & 16-20 years & 16 & 4.0 \\
& 21-25 years & 2 & 0.5 \\
& 26-30 years & 2 & 0.5 \\
\hline \multirow{4}{*}{$\begin{array}{l}\text { Duration of } \\
\text { visiting the }\end{array}$} & $1-5$ years & 343 & 85.8 \\
physician & More than 5 & 57 & 14.2 \\
& years & & \\
\hline \multirow{2}{*}{$\begin{array}{l}\text { Type of } \\
\text { treatment }\end{array}$} & Medicines & 260 & 65.0 \\
& Insulin & 100 & 25.0 \\
& Both & 40 & 10.0 \\
\hline
\end{tabular}


According to data analysis, patient satisfaction with their physician was low in $9.2 \%$, moderate in $45.8 \%$, and high in $36.0 \%$ of them. The patient's trust in the physician was low in $10.5 \%$, moderate in $49.2 \%$, and high in $35.5 \%$ of them.

\begin{tabular}{|c|c|c|}
\hline Components & Mean & SD \\
\hline \multicolumn{3}{|c|}{ Components of trust in the physician } \\
\hline Fidelity & 25.85 & 4.6 \\
\hline Competence & 23.19 & 4.4 \\
\hline Honesty & 22.7 & 4.4 \\
\hline Confidentiality & 26.2 & 5.2 \\
\hline Global trust & 20 & 3.9 \\
\hline \multicolumn{3}{|c|}{ Components of satisfaction with the physician } \\
\hline Cognitive & 36 & \\
\hline Emotional & 40.5 & 6.5 \\
\hline Behavioral & 45.6 & \\
\hline
\end{tabular}

Table 2 shows the mean scores of participants in the variables of trust in the physician and satisfaction with the physician. In addition, this Table shows the mean scores for the components of those variables.

Pearson's correlation coefficient was used to determine the relationship between trust in the physician and satisfaction with the physician. The results showed that trust in the physician and its five components were directly and significantly related to the satisfaction with the physician and its three components (Table 3 ).

Table 3 Relationship between satisfaction with the physician and its components with trust in the physician and its components

\begin{tabular}{|c|c|c|c|c|c|c|c|c|}
\hline \multirow{3}{*}{ Trust in the physician } & \multicolumn{8}{|c|}{ Satisfaction with the physician } \\
\hline & \multicolumn{2}{|c|}{ Cognitive } & \multicolumn{2}{|c|}{ Emotional } & \multicolumn{2}{|c|}{ Behavioral } & \multicolumn{2}{|c|}{$\begin{array}{l}\text { Satisfaction with the } \\
\text { physician }\end{array}$} \\
\hline & Correlations & $\mathrm{p}$ & Correlations & $\mathrm{p}$ & Correlations & $\mathrm{p}$ & Correlations & $\mathrm{p}$ \\
\hline Fidelity & 0.52 & 0.001 & 0.53 & 0.001 & 0.56 & 0.001 & 0.64 & 0.001 \\
\hline Competence & 0.57 & 0.001 & 0.58 & 0.001 & 0.57 & 0.001 & 0.65 & 0.001 \\
\hline Honesty & 0.63 & 0.001 & 0.58 & 0.001 & 0.59 & 0.001 & 0.68 & 0.001 \\
\hline Confidentiality & 0.58 & 0.001 & 0.60 & 0.001 & 0.44 & 0.001 & 0.63 & 0.001 \\
\hline Global trust & 0.71 & 0.001 & 0.68 & 0.001 & 0.65 & 0.001 & 0.72 & 0.001 \\
\hline Trust in the physician & 0.69 & 0.001 & 0.71 & 0.001 & 0.65 & 0.001 & 0.70 & 0.001 \\
\hline
\end{tabular}

Multivariate linear regression was used to determine the effect of variables of fidelity, competence, honesty, confidentiality and global trust on patient satisfaction. Five models were obtained.

Among the obtained models, the regression model with a combination of fidelity, competence, honesty, confidentiality and global trust was selected as the best model. In this model, $\mathrm{F}$ was equal to 150.612 and a significant level of 0.001 indicated that independent variables well explained the dependent variable and, in general, the regression equation was significant. The $\mathrm{R}$ coefficient was equal to 0.827 , which shows a high correlation coefficient. The explanation coefficient of the equation was equal to 0.685 which indicates that 0.685 percent of the changes related to the satisfaction with the treatment process was explained by these variables, namely, fidelity, competence, honesty, confidentiality, and global trust.

As Table 4,the global trust variable has the highest beta coefficient (0.428). The second variable in terms of beta weight is fidelity (0.203). The integrity variable $(0.124)$ is the third variable affecting patient satisfaction with the physician. The confidentiality variable $(0.118)$ is in the fourth place followed by competence $(0.101)$. 
Table 4 Simultaneous effect of the components of trust in the physician on patient satisfaction

\begin{tabular}{lccccc}
\hline $\begin{array}{l}\text { Independent } \\
\text { variable }\end{array}$ & $\mathrm{B}$ & $\begin{array}{c}\text { Standard } \\
\text { deviation }\end{array}$ & Beta & T-value & $\begin{array}{c}\text { Significance } \\
\text { level }\end{array}$ \\
\hline Fidelity & 0.910 & 0.186 & 0.203 & 4.908 & 0.000 \\
Competence & 0.468 & 0.212 & 0.101 & 2.204 & 0.028 \\
Honesty & 0.571 & 0.220 & 0.124 & 2.600 & 0.010 \\
Confidentiality & 0.468 & 0.169 & 0.118 & 2.774 & 0.006 \\
Global trust & 2.169 & 0.246 & 0.428 & 8.833 & 0.000 \\
\hline
\end{tabular}

\section{Discussion}

The patient-physician relationship and its features are among the important issues that affect satisfaction with medical services, especially satisfaction with the physician. Trust is defined as expecting observation of and certain response to the present and future needs, the ability to rely on, and ultimately faith in another person [26]. The results of this study showed that $45.8 \%$ of diabetic patients who had to have a continuous relationship with their physician due to their disease, had a moderate satisfaction with their physician; and $49.2 \%$ and $35.5 \%$ of the participants had a moderate and high trust in their physician, respectively. The results of the correlation test showed that the five components of trust had a meaningful and positive relationship with the three components of cognitive, emotional and behavioral satisfaction. As Robinson and Heritage [30] suggested, the patient-physician relationship can affect patient satisfaction in two ways: instrumental and affective. Since trust in the physician has instrumental and affective aspects, it can be said that in the present research, the instrumental and affective aspects of patient-physician relationship led to patient satisfaction with the physician.

The global trust has the highest beta score $(0.428)$. The second variable in terms of beta weight is fidelity (0.203). The integrity variable $(0.124)$ is the third variable affecting patient satisfaction with the physician. The confidentiality variable $(0.118)$ is in the fourth place followed by competence (0.101).

As the results showed, the variables of global trust, dutifulness, honesty, confidentiality, and competence had the greatest impact on the variable of patient satisfaction with the physician, respectively. North Carolina showed that the greatest dissatisfaction of patients was due to disrespect, failure to meet medical expectations, providing inadequate information to the patient, lack of timely access to the physician, lack of inter-professional communication, lack of information provision and distrust with the physician (All of these categories were among the indicators in the questionnaire in the present study) [31]. It appears that the patient-physician relationship is one of the main factors associated with patient satisfaction $[16,20]$.

In addition to the above, the results of oneway ANOVA showed that patients who had a longer visit to a physician had a higher degree of satisfaction $(\alpha=0.05)$. However, the relationship between these two variables can be interpreted in two ways. As it is expected that patients' long-standing relationship can increase their satisfaction, it can also be assumed that the initial satisfaction of the patients with the physician would lead to permanent and frequent visits to the physician. In fact, some scholars believe that satisfaction with the components of the health system leads to its frequent use [32]. In the present study, patient satisfaction increased with patients' age $(\alpha=0.05)$. One of the reasons for this positive relationship is the possibility of longer and more frequent visits of adult patients compared to young patients. This finding is consistent with previous researches in Iran [33]. The results of the research showed that the satisfaction of male patients is more than that of female patients $(\alpha=0.05)$. Although this finding is not consistent with some research in Iran [34,35], women appear to be dissatisfied 
with the physician because of their accuracy in social relationships and emphasis on the poor communication of the physician. Patients with higher education reported less satisfaction than low-educated patients.

Despite the importance of the relationship between trust in the physician and satisfaction with the physician $[9,19]$, the number of research in this area is very few both in Iran and other countries. In Iran, no research has been specifically conducted on the patient's trust in the physician, and this made serious challenge for comparing the findings of the present study with the previous studies. Therefore, it was tried to make a comparative analysis with the results of research conducted in the field of patientphysician relationship.

It should be noted that this research faced some limitations, including some patients' poor cooperation with the researcher, the busy environment, and participants' tiredness.

\section{Conclusion}

The first strategic plan of Iran medical ethics points out the importance of patient trust in the physician and considers its reduction as a serious challenge to the health system of the country. Therefore, studying trust in the medical profession and its effects on patient satisfaction as a healthcare receiver is of particular importance in Iran's treatment system. Nearly half of the study patients expressed a moderate trust and satisfaction. Considering the nature of diabetes and the need for continued care and treatment along with the constant communication between the physician and the patient, the need for high levels of trust and satisfaction with the physician is obvious. Therefore, improvement of the physician-patient relationship can be planned by emphasizing the smallest points which lead to distrust and thus reduced patient satisfaction, in order to lack of disconnect to continuous human contact chain of the two poles in the treatment system.

\section{Acknowledgemnets}

We would like to thank all the respectable physicians who allowed us to interview their patients in their workplace. We sincerely thank all the patients who collaborated in this research. This paper was extracted from a Master's thesis in the Shahid Bahonar University of Kerman, Iran, and was sponsored by the Infectious and Tropical Diseases Center Research, the HSR Research Committee, Kerman University of Medical Sciences, Kerman, Iran.

\section{Contribution}

Study design: SG

Data collection and analysis: LR

Manuscript preparation: SG

\section{Conflict of Interest}

"The authors declare that they have no competing interests."

\section{Funding}

The authors received financial support for research from research center for tropical and infectious diseases, Kerman university of medical sciences.

\section{References}

1- Simons Y, Caprio T, Furiasse N, Kriss M, Williams MV, O'Leary KJ. The impact of facecards on patients' knowledge, satisfaction, trust, and agreement with hospital physicians: a pilot study. J Hosp Med2014; 9(3): 137-41.

2- Borkar S. Empathy in physician-patient relationship: the construct and its applicability to India's health care. Social Change September2014; 44(3): 423-38.

3- Zali MR. The novel principles of patient-doctor relationship: the guidelines for good clinical practice proposed on the basis of current views in medical ethics. Second edition. Tehran: Sina Cultural-Legal Institute, Legal Publishing; 2008.

4- Magnezi R, Bergman LC, Urowitz S. Would your patient prefer to be considered your friend? Patient preferences in physician relationships. Health Educ Behav2015; 2(2): 210-9.

5- Venetis MK, Robinson JD, Turkiewicz KL, Allen M. An evidence base for patient-centered cancer care: a meta-analysis of studies of observed communication between cancer specialists and their patients. Patient Education and Counseling2009; 77(3): 379-83.

6-Pearson SD, Raeke LH. Patients' trust in physicians: many theories, few measures, and little data. $J$ Gen Intern Med2000; 15(7): 509-13. 
7- Schildmann J, Ritter P, Salloch S, Uhl W, Vollmann J. 'One also needs a bit of trust in the doctor a qualitative interview study with pancreatic cancer patients about their perceptions and views on information and treatment decision-making. Ann Onc2013; 24(9): 2444-9.

8- Hall MA, Camacho F, Dugan E, Balkrishnan R. Trust in the medical profession:conceptual and measurement issues. Health Serv Res2002; 37(5): 1419-39.

9- Berrios-Rivera JP, Street RLJr, Garcia Popa-Lisseanu MG, et al.Trust in physicians and elements of the medical interaction in patients with rheumatoid arthritis and systemic lupus erythematosus. Arthritis Rheum2006; 55(3): 385-93.

10- Bonds DE, Foley KL, Dugan E, Hall MA, Extrom P. An exploration of patient's trust in physicians in training. $J$ Health Care Poor Underserved2004; 15(2): 294-306.

11- Nelms E, Wang L, Pennell M, et al. Trust in physicians among rural medicaid-enrolled smokers. $J$ Rural Health2014; (30): 214-20.

12- Gilson L. Trust and the development of health care as a social institution. Soc Sci Med2003; 56(7): 1453-68.

13- O'Malley AS, Sheppard VB, Schwartz M, Mandelblatt $\mathrm{J}$. The role of trust in use of preventive services among low-income African-American women. Prev Med2004; 38(6): 777-85.

14- Hall MA, Dugan E, Zheng BY, Mishra AK. Trust in physicians and medical institutions: what is it, can it be measured, and does it matter? Milbank Q2001; 79(4): 613-39.

15- Calnan M, Rowe R. Researching trust relations in health care, conceptual and methodological challenges an introduction. J Health Org Manage2006; 20(5): 349-58.

16- Zahednezhad H, Poursharifi H, Babapour J. Relationship betweeh health locus of control, slip memory and physician-patient relationship with adherence in Type II diabetic patients. Bimonthly Journal of Urmia Nursing And Midwifery Faculty2011; 9(2): 249-58.

17- Mackinley RK, Roberts C. Patient satisfaction with out of hours. Primary medical care. Quality Health Care2001; 10(1): 23-8

18-Saadati Z. Satisfaction of clients referring to emergency wards of a teaching hospital in Mashhad city. Faculty of Nursing of Midwifery Quarterly2006; 16(52): 40-7.

19 -Khademnezhad S. View of patients referred to general practitioners and specialist outside the university about the doctor patient relationship. [dissertation]. Tabriz university of medical sciences 2006. pp: 91-5.

20- Seidi M, Hydary A, Reis Karami SR. Medical and Nursing Services and Patients' Satisfaction Level. Iran Journal of Nursing2005; 17(40):55-61

21- Afkham Ebrahimi A, Nasr Esfahani M, Saghafi N. Patients' expectations and satisfaction with their treating physician I II III. Razi Journal of Medical Sciences2004; 11(41): 367-76.
22- Lee YY, Lin JL. The effects of trust in physician on self-efficacy, adherence and diabetes outcomes. Soc Sci Med2009; 68(6): 1060-8

23- Shojaee AA, Abolhassani Niaraki F. The role and consequences of trust in physician-patient relationship. Iranian Journal of Medical Ethics and History of Medicine2012; 5(4): 27-35.

24- Salehian T, Safdari Dah Cheshmeh F, Pirak A. Patients' satisfaction from medical and nursing services in Khatam Alanbia hospital in Iranshahr. Journal of Gorgan Bouyeh Faculty of Nursing \& Midwifery2010; 7(2): 33-41.

25- Noorossana R, Rezaeian S, Moradi S, Rezaeian Z. Assessment of patients' satisfaction from general physicians' services: a cross-sectional study from Iran. Medical Ethics Journal2012; 6(22): 161-84.

26- Ishikawa H, Takayama T, Yamazaki Y, Seki Y, Katsumata N. Physician-patient communication and patient satisfaction in Japanese cancer consultations. Soc Sci Med2002; 55(2): 301-11.

27- Bachinger SM, Kolk AM, Smets EM. Patients' trust in their physician-psychometric properties of the Dutch version of the "wake forest physician trust scale". Patient Educ Couns2009; 76(1): 126-31.

28-Larijani B. Physician and ethical considrations: applications. Tehran: Baraye farad pub.2004.

29- Wolf MH, Putnam SM, James SA, Stiles WB. The medical interview Satisfaction scale: development of a scale to measure patient perceptions of physician behavior. J Behav Med1978; 1(4): 391-401.

30- Robinson JD, Heritage J. The structure of patients' presenting concerns: the completion relevance of current symptoms. Soc Sci Med2005; 61(2): 481-93.

31- Wofford MM, Wofford JL, Bothra J, KendrickSB, Smith A, Lichstein PR. Patient complaints about physician behaviors: a qualitative study. Acad Med2004; 79(2): 134-8.

32- Joolaee S, Hajibabaee F, Jafar Jalal E, Bahrani N. Assessment of patient satisfaction from nursing care in hospitals of Iran university of medical sciences. Journal of Hayat 2011, 17(1): 35-44.

33- Bakhtiari A, Hadj-Hasani A. The effective parameters on the patient satisfaction level of the referral patients to the out-patient physiotherapy clinics of the Semnan medical sciences university (second half of the year 2001). Journal of Semnan University of Medical Sciences (Koomesh) 2005; 6(2): 167-74.

34- Sotoodehnejad AR, Vahedian J, Fathizadeh S. Kerman university hospital patient satisfaction with medical staff in June 1997. Teb Va Tazkiey1998, 7(1): 100-4.

35- Golafrooz Shahri M, Heydari A, Farsadpoor M. Frequency of cerebral damage in CT scans of patients admitted to CT scan center of Emdad 
Hospital. Journal of Sabzevar University of Medical

Sciences2009;16(1):57-61.

Copyright@ 2016 ASP Ins. This open-access article is published under the terms of the Creative Commons Attribution-NonCommercial 4.0 International License which permits Share (copy and redistribute the material in any medium or format) and Adapt (remix, transform, and build upon the material) under the Attribution-NonCommercial terms. 